Whatever Happened to Brodrick?

D. L. Kerr, M.R.C.G.P.; J. D. J. Havard, M.D. 117

Danger of Oxytocin Infusion to the Fetus

J. M. Gate, F.R.C.o.G..............118

Jaundice after Halothane

B. R. J. Simpson, F.F.A.R.C.S., and others. . . 118

Coping with Nose-bleeds

J. McNeill, F.R.C.S.GLASG.; J. Siegler, F.R.C.S.;

J. E. A. Knowles, F.R.C.S.ED. . . . . ......118

Streptokinase and Heparin in Treatment

of Pulmonary Embolism

W. A. L. MacGowan, F.R.C.S.I. . . . . . . . 119

Diet and Colonic Cancer

T. S. Low-Beer, M.R.C.P... . . . . . . . . 119
Continuous Diaphragm Sign of

Pneumomediastinum

P. MacPherson, F.F.R., and J. S. H.

Davidson, F.F.R..................119

Doctors, Drivers, and Confidentiality

W. L. Neustatter, F.R.C.P............ 120

Death during Dental Anaesthesia

D. B. Bamber, F.F.A.R.C.S. . . . . . . . . . 120

Pre-eclampsia and the Kidney

G. J. Sophian, F.R.C.o.G.; E. N. Wardle,

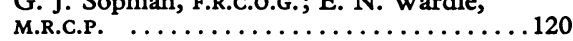

Widal Tests for Water Workers

A. F. M. S. Rahman, M.R.C.PATH., and M. E.

Cowan, F.I.M.L.T. ...............121
Treatment of Acute Gout

D. I. Haslock, M.D............... 121

Fascioliasis

C. R. Ashton, B.M., and O. D. Beresford,

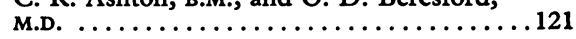

Hospital Medical Manpower

D. B. Brown, F.R.c.o.G...........121

Working Hours of Junior Staff

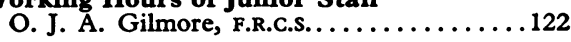

Remuneration

C. A. Price, M.R.C.G.P.; S. B. Datta,

M.R.C.P.ED. . .................... 122

Tax Relief for the Locum Consultant

N. S. Craig, M.D................ 122

\section{Whatever Happened to Brodrick?}

SIR,-The answer you provide to your rhetorical question (leading article, 30 March, p. 589) is incomplete. The work of the Committee on Death Certification and Coroners was not merely pigeon-holed by the Home Office, it was also quickly forgotten by all the organizations which had contributed so fruitfully to its deliberations.

Nobody, even at B.M.A. House, could have been so naive as to suppose that a subject as recondite as one of several studied by the Brodrick Committee would have forced itself on the attention of any Home Secretary without consistent pressure from interested and informed quarters. At one period of its deliberations the committee was urged to publish its report in time for action to be taken on it when recasting the system of local government in England and Wales. Are my colleagues who shared the six years of travail smiling wryly with me as 1 April 1974 makes of us in that context, if in no other, bigger April Fools than most?

The irony of the Brodrick Committee's report (and those of us who served on the committee recognized this) is that nearly all its recommendations were little more than a list of current practices, progress already achieved, or changes made inevitable by the demands of technical developments. Why this all needed "further study" by the Home Office I shall never understand. Its magnificent staff of civil servants advised us constantly, guided us incessantly, and finished our work by writing the report for us.

I hope your belated leading article will provoke some stirrings among organizations and individuals with some concern over the problems Brodrick tried to solve. The new Home Secretary last held the post when the Brodrick Committee was in session. I am sure he will recall its work. He might be persuaded to act on its proposals.-I am, etc.,

Thornton Heath, Surrey

DAVID KERR

SIR,-The reason why nothing has happened to the Brodrick Report (leading article, 30 March, p. 589) may be found in the defects of the report itself, which is full of tendentious reasoning and sadly lacking in scientific evidence for the more sweeping of its recommendations such as the total abolition of cremation safeguards. The report states that the committee "decided not to burden our Report with too many detailed references to the views and arguments of our witnesses. We identify the views of individual witnesses or organizations only where the context suggests that identification will be helpful" (Introduction, para. 10); and this is usually restricted to evidence in favour of the report's recommendations. We are also told that the committee commissioned two public opinion polls, the findings of which "form a very important part of our evidence"-but no information about the results of these polls is given in the report.

As pointed out in your leading article the report discounted the "alarming assertions" contained in my own book, one of which was that a number of cases of thallium poisoning must have been disposed of as natural deaths as a result of failure to distinguish such cases from polyneunitis. This "alarming" assertion, based on authenticated cases, was dismissed by the Brodrick Committee in the following words: "Common sense suggests to us that the calculating murderer who assesses the probable consequences of any course of action is likely to conclude that the risks involved in attempting to pass off murder for a natural death are not worth taking" (para. 4.35); and to put the issue beyond doubt: "Our general conclusions are that the risk of secret homicide occurring and remaining undiscovered as a direct consequence of the state of the current law on the certification of death has been much exaggerated, and that it has not been a significant danger at any time in the past 50 years" (para. 4.37). It may well be that the Government's reluctance to act on the report may have something to do with the fact that a few months after it was published the details of the Graham Young case were made known, in which a number of victims had been murdered by thallium, at least one of whom had been certified dead from polyneuritis.

Your leading article must be warmly weloomed as drawing attention to the sad state of forensic medicine in Britain, but it would be a mistake to assume that the recommendations in the Brodrick Report could provide a remedy. It goes no farther than to concede that a small number of medical schools (not more than four or five) should be allowed to teach forensic pathology. Such a proposal in relation to one of the largest technically developed countries in Europe must be regarded as cynical in the extreme. Foreign observers who generally admire our legal system have been badly shaken by this report, not only because of its misunderstanding of the foreign systems to which it refers, but also because of its failure to recognize the importance to the community of thorough medicolegal investigation of sudden and unexplained death. It would be difficult to improve on the verdict of the professor of 